\title{
Celebrating 25 Years of Homœopathic Links
}

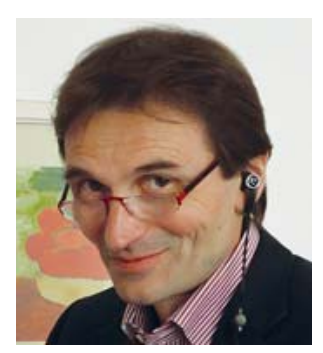

Some two years ago, I exchanged with Harry van der Zee my idea that homeopaths should share their views before publication. Copublishing is a standard procedure in science - yet not so much so in homeopathy. He thought it a nice idea, but he figured it might be hard to realise. Homeopaths, he added, prefer to think and work independently. But, I replied, wouldn't their conclusions become more precise and comprehensive were homeopaths to discuss their findings before publication? They would have collected their findings, exchanged their ideas, compared their opinions and finally have published together. My wise friend did not want to argue with me and did not say much more.

Almost a year ago, he invited me to be guest editor for the very issue you are now holding in your hands. He suggested inviting papers from colleagues who had participated in the 20th anniversary Links conference in Heidelberg in 2007. Five years later, a redefinition of the position of homeopathy could be made.

So, my wise friend gave me the opportunity to promote my own idea. While inviting all those experienced teachers and homeopathic healing artists, I could ask them not only to participate in this Celebration Issue, but also to exchange their ideas before publication. They could express what topic they were interested in and invite others to join them. To my great joy, the idea was accepted. Not by everyone, but by some. (My dear friend, you are right: homeopaths tend to work and think independently. I look at it positively - it is a great gift that they are capable of doing so.) Finally, in this issue we read a great number of superb papers. I am very grateful to all of you for sharing your experience with the community. You even respected the deadline, which is always a nuisance!

Extra thanks go to those who plunged straight into cold water. Interested in similar topics, as became clear during the initial circulars, and without knowing each other, they took the risk. They started to exchange their ideas and finally published jointly. Every opinion has been respected and, as I was told, the whole has become more than the sum of its parts would have been.

This could be one more way to link homeopaths. I like it. What about you?

Franz Swoboda, Guest Editor

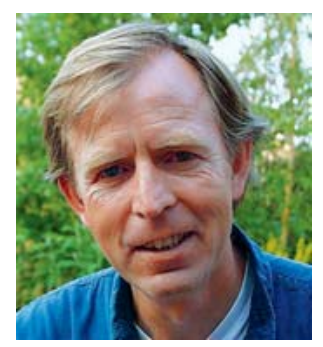

Let me start by thanking Franz for his vision for this Celebration Issue and the dedication and gentle persuasion with which he persevered to realise it. Like the catalyst he is, he made the alchemy possible.

Characteristically for Franz, he did not include an article himself, although I urged him to do so; and he only used half of the space for an editorial, where I had offered him all of it.

Perhaps this modesty is only a guise and actually an instrumental part of the quiet force he actually embodies. A Freudian "ran out of ink" leaves me with half a blank page and "forces" me (I'm sure Franz would prefer me to use "invites" here) to be the first to answer his "what about you?" His call for raised standards in homeopathic publications deserves an answer, primarily because it is a justified invitation, and one I happily support.

The creation of coauthored articles is certainly something l'd love to invite to the pages of Links. Especially if the authors only get to know each other through the process, this can lead to homeopathic pearls that can stand the test of time, as any form of individual or joint bias can then be avoided.

I welcome you to use the Link \& Learn column to announce the topic you wish to investigate and publish on and to invite others to join you in the creative process.

Although not officially stated, more and more articles in Links are being peer reviewed - another scientific standard - and every article is being read and commented on by at least two homeopaths.

Still, this would not be Links if a striving for standards were to become a fixation on rules, and if the communication between friends and colleagues - the way in which it all began - were to turn into scientific articles which no longer touch our hearts and souls. The current issue is an example of the fine balance that can be reached. My congratulations to Franz and the many authors who have contributed to this issue, and to you dear readers who have helped Links to reach this respectable age of 25!

Harry van der Zee, Editor 